\title{
Extracting Good Ventilation Design from Chino-Portuguese Commercial Building in the Old Town of Songkhlafor the Design of New Commercial Building
}

\author{
Sittichoak Sae-poo ${ }^{1}$, and Kuaanan Techato ${ }^{1}$ \\ Faculty of Environmental Management, Prince of Songkla University
}

\begin{abstract}
This research had proposed the good ventilation design learned from Chino-Portuguese commercial buildings located in Songkhla old town area in order to be used for the new commercial buildings design.The building physical characteristics were studied and simulated by the Computational Fluid Dynamics, CFD. The simulation had been done for 3 groups classified by spaces and functioned area including ventilation. The first group has no ventilation in the middle court area. The second group has ventilation at the middle court area. The third group has almost two times of the middle court area of previous group. It is found that the second group has good ventilation for resident and effective in term of area using. This result can be developed into the guideline of commercial building design corresponding to the need of resident to have good ventilation, leading to the energy saving.
\end{abstract}

Keywords: Good Ventilation Design, Chino-Portuguese, Commercial Building

\section{Introduction}

Songkhla province in Thailand was an important harbor city for various trading between eastern and western. The mixing of culture is thus happened in Chino-Portuguese style (China and Portugal) of row houses, shop houses, row buildings, town houses twin houses, and commercial buildings. The architecture in the old town area of Songkhla province is classified into 4 period i.e. Thai and original China for more than 100 years, Chino-Portuguese 60-100 years, Chinese commercial buildings 30-100 years, and modern buildings not more than 60 years. Besides the appearance, the dominant feature of buildings in the old town is the ventilation and comfort zone. There is front court with accordion door, middle open court, and back court (1). The renovation of chino-Portuguese is sometimes ignored the ventilation causing the requirement of air-conditioner installation. The energy consumption increases as the cooling load (2). The ventilation of Chino-Portuguese hence could be adapted to the new commercial buildings.

The objectives of the research is to study the ventilation feature of Chino-Portuguese buildings in the old town area of Songkhla and to propose the ventilation design guideline adapted from the Chino-Portuguese buildings to meet the comfort zone.

The open court in Chino-Portuguese buildings is categorized into front, middle, and back area. The windows and doors are also a part of ventilation.

\section{Methodology}

\subsection{Survey the old town buildings in Songkhla Province}

The majority of buildings are located facing to the north direction. These group is selected for studying. From 97 buildings, 6 buildings, house number 64, 66, 72, 86, 92, and 240, are selected to be the prototype of the study as the difference of open court area.

\subsection{Collect the data of open court area}

Collect the data of open court area in front of, middle, and at the back of the building including the height in order to be able to calculate the volume and to simulate as prototype. 


\subsection{Measure the velocity}

Measure the velocity at each open court together with the open area such as windows and doors. Simulate data by the CFD software.

\section{Results}

The building which has the highest average wind speed and the building which has the lowest average wind speed has a big difference in the characteristic of the building in term of having the open court. One with open court will reflect the dominant role in ventilation.

The building prototype is created for the investigation of the ventilation by using CFD software with last 5year meteorology data, background wind speed, 2011-2015 of Sonkhla.The prototypes are classified into 3 groups. The first one is the group with front, middle, and the back court but the middle court is closed without ventilation. The second group has front, middle, and back court and the middle court has no roof in the middle court for the purpose of ventilation. The third group has front, middle, and back court and the middle court is about $50 \%$ of the total area without roof.

The longitudinal ventilation of 6 buildings by CFD is shown in fig 1 and in the vertical direction is in figure 2. The average speed is in figure 3. The darker dot in the figure 1 and 2 means the higher of velocity. The darker dot in the figure 1 and 2 means the higher of velocity.

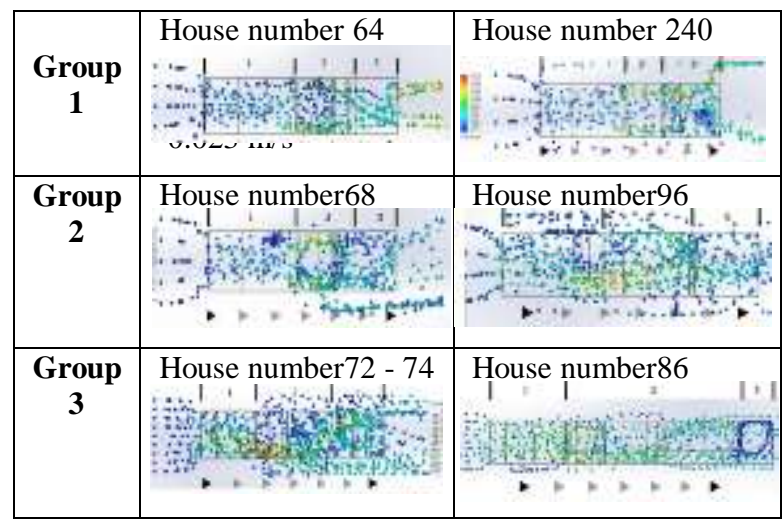

Fig 1 Longitudinal ventilation of 6 buildings by CFD

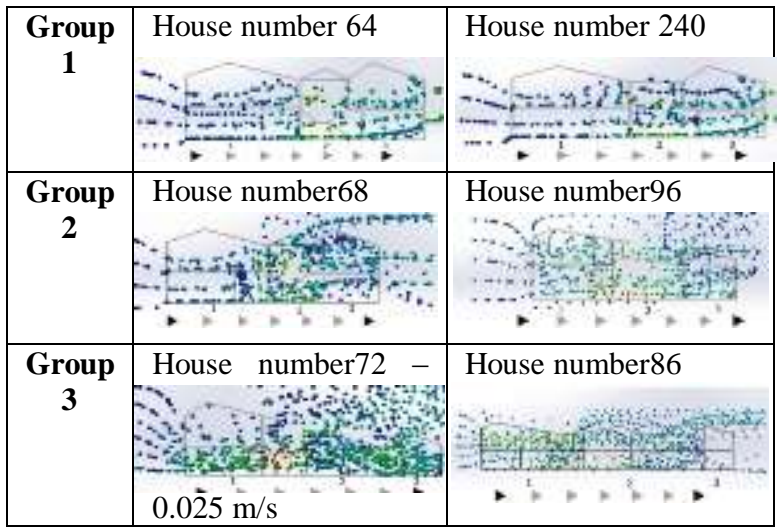

Fig 2 Vertical ventilation of 6 buildings by $\mathrm{CF}$

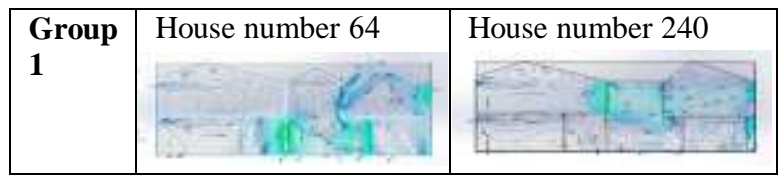




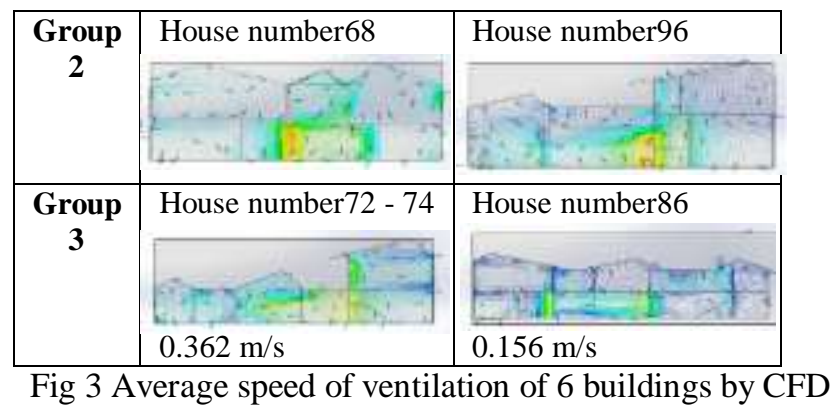

\section{Conclusion}

The average wind speed in group 1 building is $0.256 \mathrm{~m} / \mathrm{s}$. The average wind speed in group 2 building is $0.580 \mathrm{~m} / \mathrm{s}$. The average wind speed in group 3 building is $0.440 \mathrm{~m} / \mathrm{s}$. The building in group 1 has lowest wind speed because there is no open court in the middle area whereas the wind speed in group 2 had the best or highest wind speed because of the availability of the middle open court area. The wind speed of group 3 show that the greater area of the middle open court does not reflect the better ventilation.

\section{Suggestion}

The design of commercial building paid attention to the space utilization but ignore the ventilation which can be achieved by the passive design. The air-conditioning is therefore a must for the commercial building. The energy consumption is inevitably high for commercial buildings.

\section{Acknowledgements}

This work was supported by Asia Research Center, Chulalongkorn University Interim Report Form, Chulalongkorn University, Thailand.

\section{References}

[1] P. Tepsing and T. Promsaka Na Sakolnakorn (April 2014). The Sino-Portuguese Architectural Identity of Chinese Descendants and Sustainable Development in Phuket, Thailand. The International Journal of Sustainability in Economic, Social and Cultural Context [Online]. 9(3). pp. 1-11. Available: http://ijsesc.cgpublisher.com/product/pub.273/prod.72

[2] W. Karnchanawiroj, "AN INVESTIGATION OF EXTENDED COMFORT ZONE IN HOT-HUMID CLIMATE" M.S. thesis, Faculty of Architecture (Building Technology), Chulalongkorn University. Bangkok, Thailand, 1998. 